\title{
PENGGUNAAN TINGGALAN BATU PAMALI SEBAGAI MEDIA PELANTIKAN RAJA DI DESA LIANG KEC. TELUK ELPAPUTIH KABUPATEN MALUKU TENGAH
}

\author{
The Use of Batu Pamali as a Medium of King's Inauguration at \\ The Liang Village of Elpaputih District Central Moluccas Regency
}

Karyamantha Surbakti

Balai Arkeologi Ambon

Jln. Namalatu Latuhalat Ambon 97118

e-mail: mansurtorong@yahoo.com

Naskah diterima : 03-03-2014 ; direvisi : 12-08-2014 ; disetujui :05-09-2014

\begin{abstract}
The Scattered remains of the prehistoric period in the Moluccas is patterned megalithic artifacts. Such objects are usually stillin contact with communal society and often used as a megalithic tradition. The purpose of research is to look at the dimensions of contemporary culture and taboos of the stone used as a medium for the inauguration rite father the king. The method used in this study is a qualitative approach and the approach etnoarkeologi. Obtained from this study is a holistic picture that taboos are still preserved remains of stone used in communal societies. Research conclusions obtained is that the tradition continues the use of stone as a medium pamali rite inauguration of the king is a wealth of local cultural repertoire.
\end{abstract}

Keywords: Stone Pamali, Megalithic Tradition, Rites, Inauguration of the King

\begin{abstract}
Abstrak
Tinggalan masa prasejarah yang tersebar di daerah Maluku adalah artefak yang bercorak megalitik. Benda tersebut biasanya masih bersinggungan dengan komunal masyarakat dan acapkali digunakan sebagai tradisi megalitik. Tujuan penelitian adalah untuk melihat dimensi kebudayaan dan kekinian dari batu pamali yang digunakan sebagai media ritus pelantikan bapa raja. Metode yang digunakan dalam penelitian ini adalah pendekatan kualitatif dan pendekatan etnoarkeologi.Hasil yang diperoleh dari penelitian ini adalah sebuah gambaran yang holistik bahwa tinggalan batu pamali masih lestari digunakan dalam komunal masyarakat. Kesimpulan penelitian yang diperoleh adalah bahwa tradisi berlanjut yang menggunakan batu pamali sebagai media ritus pelantikan raja merupakan khasanah kekayaan budaya lokal.
\end{abstract}

Kata Kunci: Batu Pamali, Tradisi Megalitik, Ritus, Pelantikan Raja.

\section{PENDAHULUAN}

Tinggalan megalitik secara umum diketahui berkembang mulai masa bercocok tanam atau pada tingkat kehidupan neolitik. Kehidupan budaya ini berlangsung dalam kurun waktu yang cukup lama dan tersebar hampir merata di seluruh Indonesia, misal Jawa, Sumatera, Bali, Sulawesi, Nias dan pada daerah Indonesia bagian timur. Hingga sekarang tradisi ini masih terus berkembang di beberapa wilayah Indonesia. Berdasarkan lokasinya, tinggalan megalitik ini pada umumnya terletak pada daerah dataran tinggi, meskipun ada beberapa di antaranya terdapat pula pada dataran rendah.

Persebaran umum yang ditempuh oleh pendukung tradisi megalitik tersebut adalah dari daratan Asia, kemudian melalui 
semenanjung Malaka dan terus ke Indonesia menerobos pulau Sumatera. Hal ini karena adanya unsur-unsur lokal yang membawa perbedaan hasil tradisi megalitik it (Sukendar, 1982 : 89). Persebaran itu rupanya terjadi perbedaan-perbedaan dari tinggalan di berbagai wilayah di Indonesia, sehingga setiap wilayah mempunyai persamaan, perbedaan dan ciri khusus. Hal ini dapa dilihat misalnya di Sulawesi Tengah ditanda oleh adanya bejana batu dengan penamaan lokal kalamba,di Lampung ditandai oleh dolmen, di Gunung Kidul ditandai oleh peti batu, di Bondowoso ditandai ole phandusa, di Bali dikenal dengan batu kukuk dan beberapa temuan sarkofagus dan lain sebagainya.

Bentuk bangunan megalitik bermacam-macam jenisnya yang dibangun dengan maksud utama dari pendiriannya adalah berlatar belakang pemujaan arwah nenek moyang, pengharapan kesejahteraan bagi yang masih hidup, dan kesempurnaan bagi si mati. Bangunan yang paling tua mungkin berfungsi sebagai kuburan dengan bentuk yang beraneka ragam. Bentuk-bentuk tempat penguburan dapat berupa dolmen, peti kubur batu, bilik batu, sarkofagus, kalamba, atau bejana batu, waruga, batu kandang dan batu temu gelang. Tempat kuburan semacam ini biasanya terdapat beberapa batu lainnya sebagai pelengkap pemujaan nenek moyang, seperti menhir, arca, batu saji, batu lumpang, batu lesung, atau batu dakon, pelinggih batu, tembok batu atau jalan berlapis batu (Soejono, 1996 : 211).

Bangunan megalitik di Indonesia mempunyai bentuk dan fungsi yang sangat kompleks. Demikian halnya dengan pemberian nama, tinggalan megalitik sering diberi nama-nama lokal sesuai dengan nama daerah setempat. Bentuk-bentuk bangunan megalitik menurut fungsinya sering dikaitkan secara mengkhusus sebagai perwujudan nenek moyang, penolak bahaya, tempa penguburan dan sarana media ritual tertentu. Tradisi megalitik mengalami perkembangan memuncak pada masa perundagian atau pada masa kemahiran teknologi, yaitu kira-kira menjelang awal atau sesuda tarikh Masehi. Masa ini dianggap sebaga akhir masa prasejarah yaitu menjelang datangnya anasir pengaruh Hindu dan Budha yang ditandai dengan kegiatan masyarakat mendirikan bangunan-bangunan megalitik, seperti menhir, dolmen, tahta batu, punden berundak, onggokan batu alam dan lainnya yang berkaitan erat dengan pemujaan arwah nenek moyang. Kepercayaan terhadap arwah nenek moyang adalah awal dari kepercayaan terhadap kekuatan alam seperti kekuatan gunung atau kekuatan laut, dan kepercayaan kepada pemberi kesuburd atau pemberi kemakmuran, karena arwah nenek moyang dianggap berada di puncak gunung sehingga gunung dipandang sebaga dunia arwah yang menyimpan kekuatan magis yang besar. Berpangkal kepada pandangan ini maka gunung dianggap keramat dan merupakan pusat sumber daya alam yang dapat memberikan kesejahteraan dan kemakmuran kepada masyarakat (Wales, 1953 : 92-119).

Daerah Maluku memiliki tinggalan tradisi megalitik utamanya dolmen dengan sebutan batu pamali (batu yang dikeramatkan). Dolmen tersebut ma Dolmen tersebut masih difungsikan dengan ritual tertentu sebagai tempat memint kekuatan, mengasah parang dan sebagai tempat menyumpah kepala adat/desa yang baru dilantik. Penelitian di desa Eti berhasil menemukan dua buah dolmen dan di desa Oma ditemukan empat buah dolmen yan pada masa lampau menunjukkan sebuah fungsi sebagai upacara kakehang (upacara pendewasaan anak), selain itu juga dolmen difungsikan sebagai batas desa atau batas tanah perumahan (Soegondho, 1996 : 8).

$$
\text { Keanekaragaman pemanfaatan dan }
$$

fungsi dari tinggalan tradisi megalitik yang ada di daerah Maluku ini menunjukkan bahwa tradisi megalitik tersebut mempunya sifat yang sangat dinamis, yaitu berkembang sesuai dengan kebutuhan zaman. Keragaman fungsi itu juga akan memberikan nilai tambah terhadap penelitian arkeologi, yaitu dalam usaha mengungkapkan dan mempelajari pola pikir mengenai latar belakang pembuatan atau didirikannya bengunan megalitik khususnya di daerah Maluku.

Desa Liang berada di Pulau Seram, termasuk dalam Kecamatan Teluk Elpaputih yang memiliki tinggalan megalitik berupa batu pamali (batu yang dikeramatkan). Batu ini terletak persis disamping balai pertemuan desa (baileu) dan tidak jauh dari garis pantai dimana teluk Elpaputih berada. Masyarakat desa Liang sendiri masih menunjukkan adanya kepercayaan tradisional yang diwujudkan dalam ritual adat tertentu yang hingga saat ini masih dipertahankan. Salah satu tradisi tersebut adalah pengambilan sumpah kepala desa (bapa raja) menggunakan batu pamali. Berdasarkan latar belakang tersebut, maka pokok permasalahannya disusun sebagai berikut.

1. Bagaimana dinamika fungsi kekinian dari batu pamali di desa Liang, yang berkaitan dengan pelantikan bapa raja?

2. Apa saja faktor yang mempengaruhi sehingga masih dipertahankan penggunaan batu pamali pada setiap ritual pengambilan sumpah bapa raja?

Penelitian ini memiliki dua tujuan, yaitu tujuan umum dan tujuan khusus. Kedua tujuan itu dapat diuraikan sebagai berikut. Tujuan umum dari penelitian ini adalah dengan berdasarkan arkeologi sebagai sebuah disiplin ilmu tidak terlepas dari pemahaman tentang kebudayaan masa lalu yang didasarkan pada tiga tujuan yaitu rekonstruksi sejarah budaya, rekonstruksi cara-cara hidup, dan penggambaran proses budaya (Binford, 1972 : 104). Merujuk pada tiga tujuan tersebut maka penelitian ini dititikberatkan pada tujuan arkeologi yang ketiga. Secara umum juga, penelitian ini bertujuan untuk memahami pengunaan tinggalan arkeologi dalam ritual adat desa.

Tujuan khusus dari penelitian ini adalah; (a) mengetahui dinamika fungsi kekinian dari batu pamali di desa Liang, yang berkaitan dengan pelantikan bapa raja, (b) mengetahui faktor apa saja yang mempengaruhi pola pikir dalam masyara shingga masih dipertahankan penggunaan batu pamali pada setiap ritual pengambilan sumpah bapa raja

Manfaat dari penelitian ini antara ain; (a) secara teoretis, hasil penelitian in dapat membantu sumbang pemikiran ilmiah bagi ilmu pengetahuan bidang arkeologi, khususnya tentang tradisi megalitik berlanjut, sesuai dengan hakekat pendidikan, penelitian, dan pengabdian masyarakat dan kemudian (b) secara praktis, bagi pemerintah daerah, dapa menjadi masukan dalam mengambil kebijakan yang berkaitan dengan perlindungan dan pembinaan kepurbakalaan di Maluku Tengah.

\section{METODE}

Pendekatan untuk menganalisa data sangat diperlukan untuk menginterpretasi data yang berupa tangible culture (budaya benda) maupun intangible culture (budaya tak benda). Pendekatan yang pertama dalam penelitian ini adalah analisis kualitatif yaitu pengolahan data yang bersifat konsep, asumsi, dan pengertian abstrak yang diuraikan dar kualitas data. Pendekatan kualitatif juga sangat diperlukan untuk menganalisis artefak berupa batu pamali (dolmen) yang terkait dengan fungsinya kini dan faktor yang mempengaruh dolmen masih dipertahankan penggunaannya di tengah masyarakat. Pendekatan ini dikenal juga dengan pendekatan deskriptif naratif yang mencoba menarasikan data yang ada di lapangan, kemudian data-data tersebut disintesakan dan diinterpretasikan.

Pendekatan berikutnya yang digunakan dalam penelitian ini adalah analisi kontekstual ialah mengadakan analisis dengan melihat hubungan atau keterkaitan antara data yang satu dengan yang lainnya dalam tingkatan tertentu. Fokus analisis ini terutama adalah hubungan antara batu pamali (dolmen) dengan dinamika sosial masyarakat yang masih dapat diperhatikan yaitu pelantikan raja.

Pendekatan terakhir adalah menggunakan analisis etnoarkeologi yang 
dimana prinsip ini yang dipakai untuk mengetahui sejarah masa kini dan masa lalu. Terdapat premis yang menyatakan bahwa jika dua kelompok gejala memiliki kesamaan dalam hal tertentu (misalkan bentuk dan fungsi) maka keduanya mungkin akan mempunyai kesamaan pula dalam beberapa hal lainnya (misalnya cara pembuatan dan cara memakai). Dalam hal ini arkeologi digunakan untuk mengidentifikasi dan menetapkan hubungan antara data arkeolog berdasarkan perbandingan dengan gejala serupa yang masih dapat ditemukan dalam masyarakat yang masih hidup.

\section{HASIL DAN PEMBAHASAN}

Uraian dari penelitian ini dapat dilihat dari gambaran umum benda bercora megalitik yang berada di Maluku Tengah. Hal ini diperlukan untuk melihat sejauh mana temuan yang bercorak megalitik masih ada dan bersinggungan dengan komunal masyarakat dan juga untuk melihat ragam dan karakteristik benda tinggalan budaya tersebut.

Situs pertama yang dapat dijadikan contoh adalah Situs Desa Aboru. Situs in berada di gugus pulau-pulau Lease, di bawah pulau Seram atau sebelah Timur dari pulau Ambon, yang termasuk Kecamatan Pulau Haruku. Peninggalan megalitik di situs ini diantaranya berbentuk batu datar yang menyerupai dolmen, dimana tampak sebuah penyangga yang dipergunakan sebaga kakinya. Ada kemungkinan bahwa batu yan atasnya rata dan terdapat bekas asahan itu dahulu dipergunakan sebagai benda kerama dan berfungsi sebagai sarana upacara. Keadaan lingkungan sangat mendukung keberan tradisi megalitik karena di situs ini banyak trasi mat batu-batu besar situs ini banyak terdapat batu-batu besar yan dapat dipergunakan sebagai bahan bak dalam pembuatan megalit. Batu datar yan di atasnya terdapat bekas asahan banyak dijumpai pada berbagai situs megalitik. Batubatu asah seperti ini merupakan tinggalan yang sangat universal. Batu asah biasanya berkaitan dengan upacara tertentu antara lain upacara sebelum perang, dan upacara untuk menolak wabah penyakit (Istari et al, 1997

: 10).

Batu asah seperti ini juga yang ditemukan di situs Watuklotok dan situs Takirin dan biasanya dipergunakan untuk mengasah senjata yang akan dipergunakan dalam suatu peperangan. Menurut kepercayaan pendukung tradisi megalitik di daerah Timor tersebut dengan mengasah senjata yang akan diperrgunakan dalam peperangan maka mereka percaya ada kekuatan gaib yang sangat besar menaung senjata tersebut, sehingga senjata tersebu mampu membunuh setiap musuh yang dihadapi. Selain mengasah senjata pada batu asah tersebut, pendukung tradisi megalitik juga melakukan tarian ritual, agar lebih memberikan kekuatan dan kepercayaan diri dalam menghadapi musuh. Pakaianpakaian yang digunakan dalam pertempuran bukan merupakan pakaian sehari-hari tetapi merupakan pakaian khusus yang dibuat anggun dan berwarna-warni. Pakaian ini merupakan pakaian yang dipersiapkan agar musuh terperangah. Penampilah batu asah yang dibentuk sebagai dolmen (dolmen semu) ini tampak erat kaitannya dengan usaha untuk menambah kesakralan dari batu asah tersebut disamping mempunyai fungsi praktis yaitu untuk mempermudah proses upacara.

Situs yang berikut adalah Situs Desa Iha. Situs ini berada di Desa Iha, Kecamatan Saparua. Dalam kompleks Situs Desa Iha ditemukan beberapa tinggalan tadis prasejarah berupa lima buah dolmen atau meja batu. Meskipun tampak tidak terurus, tapi kondisinya cukup baik. Dolmen yang pertama adalah dolmen yang berada di deka lokasi mesjid mempunyai ukuran lebar $38 \mathrm{~cm}$ dan panjang $39 \mathrm{~cm}$. Dolmen ini mempunyai tiga buah tiang penyangga atau kaki, dan pada bagian depan papan dolmen (menyatu dengan ujung dolmen) terdapan pohon beringin kecil yang sudah dipotong. Papan batu dolmen berasal dari batu padas dan kakinya dari batu karang. Dolmen yang kedua ditemukan di sebelah timur laut dari dolmen yang pertama. Dolmen ini mempunyai ukuran yang cukup besar yaitu lebar $129 \mathrm{~cm}$, panjang $147 \mathrm{~cm}$, tebal $15 \mathrm{~cm}$, dan tinggi kaki $41 \mathrm{~cm}$. Dolmen ini terbuat dari batu padas baik papan dan kakinya. Pada bagian atas dari papan batunya terdapat sebuah lempengan batu kecil berbentuk bulat dengan diameter $30 \mathrm{~cm}$ yang terbuat dari batu kali (Sudarmika, 2000 : 12). Selanjutnya di sebelah utara dari dolmen tersebut ditemukan dolmen yang lebih kecil dengan ukuran lebar $98 \mathrm{~cm}$ dan panjang $102 \mathrm{~cm}$. Dolmen yang ketiga terbuat dari batu karang yang dibentuk datar bagian atasnya. Selain dolmen di kompleks ini juga ditemukan menhir, tinggalan ini terbuat dari batu karang yang mengalami pengerjaanpada semua bagian sisinya sehingga menjadi rata, me dari domen ketiga yang mempunyai ukuran panjang $40 \mathrm{~cm}$, lebar $19 \mathrm{~cm}$ dan tebal $9 \mathrm{~cm}$.

Bagian lain dari kompleks tersebut yaitu di sekitar bangunan baileu ditemukan dua buah dolmen lainnya yaitu dolmen Patasiwa (dolmen 9) dan dolmen Patalima (dolmen 5). Dolmen Patasiwa mempunyai ukuran lebar $153 \mathrm{~cm}$, panjang $165 \mathrm{~cm}$, tebal $4-22 \mathrm{~cm}$ dan tinggi kaki $36 \mathrm{~cm}$. Dolmen tersebut ditopang oleh tiga buah kaki yang terbuat dari batu karang, sedangkan papannya terbuat dari batu padas merah. Pada bagian atas dari papan batu dolmen ini terdapat bekas tapak kaki sebelah kanan, dan mempunyai 99 lubang besar dan kecil, sedangkan dolmen Patalima mempunyai ukuran lebar $141 \mathrm{~cm}$, panjang $149 \mathrm{~cm}$, tebal $10-15 \mathrm{~cm}$, dan tinggi kaki $0-40 \mathrm{~cm}$. Dolmen ini ditopang oleh tiga buah kaki yang terbuat dari batu karang.

Situs terakhir yang digunakan sebagai gambaran umum untuk penulisan ini adalah Situs Desa Sila. Situs ini berada di Pulau Nusa Laut, dimana di desa ini terdapat dua buah objek berkarakter megalitik dalam bentuk dolmen. Dolmen pertama yang berukuran relatif besar terdapat di dekat pantai, dan dolmen kedua yang berukuran lebih kecil terdapat di dekat baileu (balai desa). Dolmen pertama yang terdapat di dekat pantai dan hingga kini masih digunakan dalam kegiatan ritual adat. Ukuran dolmen ini adalah 23 $\mathrm{cm}$ dan tinggi $127 \mathrm{~cm}$. Dolmen kedua yang terletak dekat dengan baileu, memiliki ukuran yang relatif lebih kecil. Dolmen ini digunak sebagai wahana untuk meletakkan gendering dan hingga kini masih digunakan dalam ritual adat (Ririmasse, $2008: 6$ )

Lokasi penelitian desa Liang berada di Pulau Seram. Pulau Seram merupaka salah satu pulau di Maluku yang substansi perkembangan masyarakat sangat signifikan dengan adat dan teritorial masing-masing komunitas. Pulau Seram juga merupakan pulau terbesar di Kepulauan Maluku denga memiliki luas pulau $311 \mathrm{mil}^{2}$ sama dengan $17.130 \mathrm{~km}^{2}$, dengan bentuk pulau adalah setengah lingkaran dan memanjang dar barat ke timur (Taurn 2001 : 10). Secara astronomi Pulau Seram terletak antara 2 $69^{\circ} \mathrm{LS}-4^{\circ} 38^{\circ} \mathrm{LS}$ dan antara $127^{\circ} 44^{\circ} \mathrm{BT}$ $-131^{0} 32^{\circ}$ BT. Batas-batas geografis antara lain; sebelah Utara berbatasan dengan Lau Seram, sebelah Timur berbatasan dengan Laut Arafura, sebelah Barat berbatasan dengan Laut Buru dan disebelah Selatan berbatasan dengan Laut Banda.

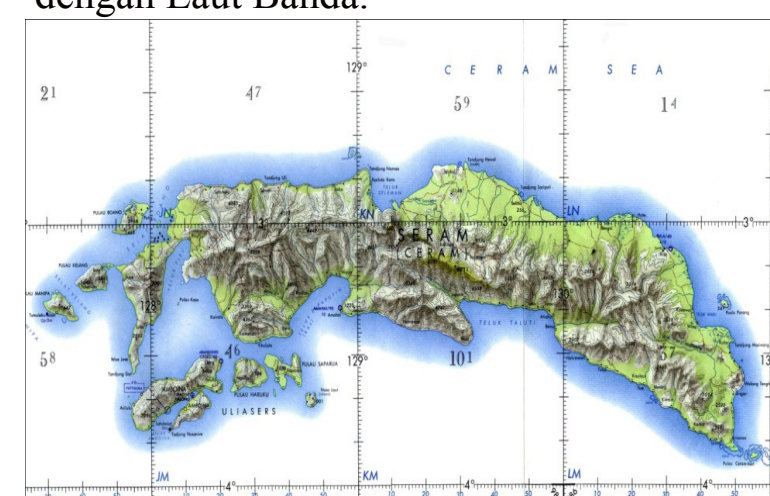

Gambar 1. Peta Pulau Seram (lokasi penelitian dalam lingkaran)

(Sumber : wikipedia.org)

Pembagian dalam kelompok masyarakat di Pulau Seram antara Patasiwa dan Patalima dapat dibagi atas dua kelompok besar yakni, kelompok penduduk pegunungan dan kelompok penduduk pesisir (Taurn 2001 36). Dengan demikian, dapat dikatakan bahwa, penduduk Seram bagian pedalaman/ pegunungan kelompok Patasiwa, sedangkan kelompok Patalima adalah di bagian pesisir Namun pada mulanya kelompok Patalima 
termasuk kelompok penduduk pegunungan. Desa Liang merupakan desa yang berada di pesisir Teluk Elpaputih dan memiliki desa tetangga seperti Rumahlait, Awaya, dan Waraka. Masyarakat setempat negeri-negeri tersebut hidup bertetangga antara satu dengan yang lain dengan masing-masing wilayah/ territorial. Desa Liang yang tergolong kelompok Patalima ini memiliki kebiasaan adat yaitu menggunakan sebuah batu pamal yang berada di tengah desa, dalam prose pengambilan sumpah bapa raja yang dilantik.

Penelitian ini merupakan penelitian deskriptif yang melihat sejauh man pengounaan batu pamali dalam masyarak desa Liang. Batu pamali tersebut relati besar serta memiliki ukuran dengan kaki penyangga yang relatif pendek. Terbuat dar batuan andesit, berwarna hitam dan agak pipih. Adapun dimensinya; panjang batu $60 \mathrm{~cm}$, dengan lebar masing-masing, lebar pangkal $43 \mathrm{~cm}$, lebar tengah $38 \mathrm{~cm}$, dan lebar ujung $15 \mathrm{~cm}$. Batu pamali ini ditopang oleh 3 kaki batu berbentuk menhir berukuran kecil. Tinggi masing-masing kaki adalah kak I: $25 \mathrm{~cm}$, menopang bagian pangkal batu pamali sebelah timur, tinggi kaki II: $21 \mathrm{~cm}$, menopang pangkal batu meja bagian barat dan kaki III: $18 \mathrm{~cm}$, menopang uj meja bagian utara. Batu tersebut berada di 40 mdpl dan terletak sekitar 15 meter dar jalan raya trans seram. Menurut penduduk setempat, batu pamali yang berada di negeri Liang sekarang merupakan batu pamali yang sebelumnya berada di negeri lama, yang dibawa serta saat penduduk berpindah ke negeri yang ditempati sekarang.

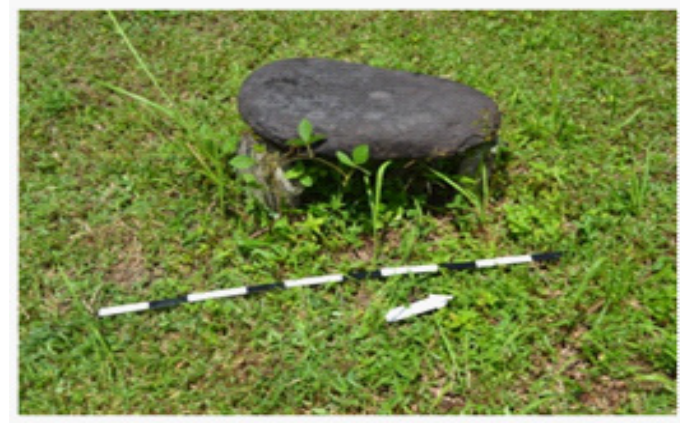

Gambar 2. Batu pamali memiliki kaki. (Sumber: Dokumen Balar Ambon 2012)
Balai Arkeologi Ambon pada pertengahan bulan Februari 2012 melakukan penelitian ke desa pesisir Tel Teluk Elpaputih, mendapat keterangan seorang narasumber yang bernama Bapa Matheo. Beliau merupakan mantan bapa raja Liang dan memiliki seorang anak laki-laki bernama Simon Tuniluhulima yang pada saat itu sedang menjabat bapa raja desa Liang. Sistem wawancara yang dilakukan terhadap narasumber adalah wawancara tanpa struktur namun dengan pertanyaan yang sudah disiapkan sebelumnya agar lebih banyak mendapen informa

Menurut pemapang beliau, akibat

Menurut pemaparan beliau, akibat pergolakan pada masa penjajahan Beland yang ketika itu masuk ke Maluku sekita tahun 1598, kelompok Soahuwey, Awaya, Rumalait, Apisano, dan Hitalesia bergabung menjadi satu dalam wilayah petuanan Tananahu, sedangkan Liang dan Waraka masih tetap pada wilayah petuanan mereka dan mempunyai pemerintahan sendiri.

Dalam sistem pemerintahan adat dan desa, kedudukan bapa raja dalam masyarakat sangat penting adanya. Pelaksanaan kebijakan yang ada di komunal masyarakat dan proses pemerintahannya sangat dibebankan kepada seorang tokoh bapa raja yang dimaksud. Hal ini menyebabkan seorang bapa raja memiliki figur yang sangat dituakan di tengah masyarakat. Sebagai simbol pemimpin dan sebagai orang yang memediasi jika tindakan musyawarah diperlukan untuk kepentingan masyarat desa. Hal tersebut mentingan masyar at desa Hal tersebut merupakan sebuah pandangan yang diketahui oleh masyarakat secara personal memandang pemimpinnya, yang dalam hal ini sosok bapa raja Liang.

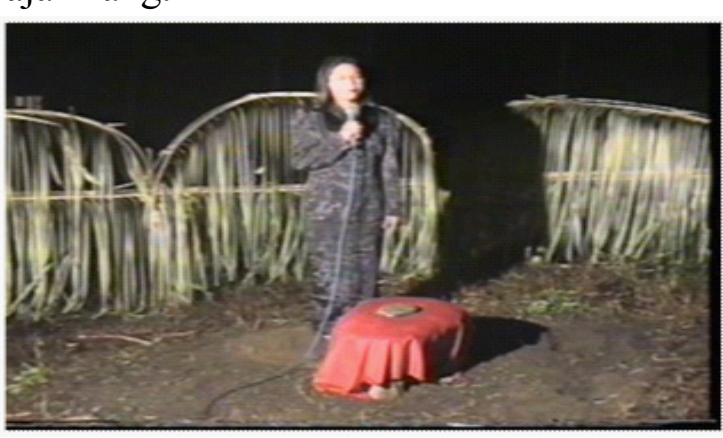

Gambar 3. Persiapan di depan batu pamali (Sumber: Dokumen Balar Ambon 2012)

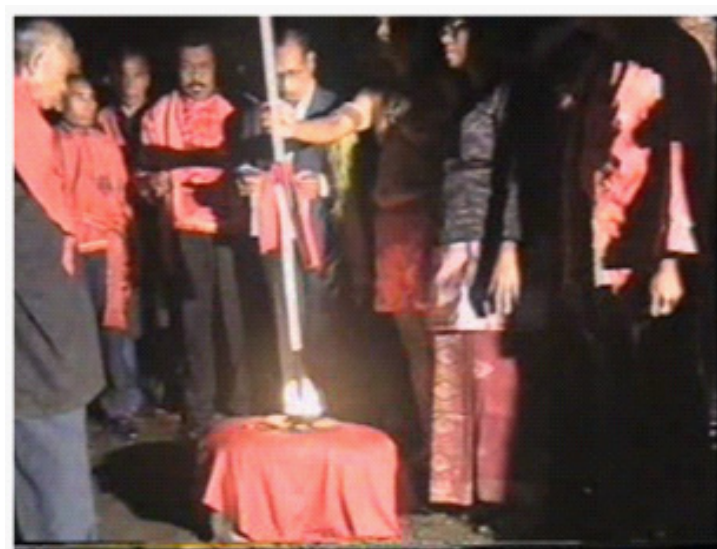

Gambar 4. Pelantikan menggunakan media batu pamal

(Sumber: Dokumen Balar Ambon 2012)

Pada saat wawancara dengan Bapa Matheo yang juga didampingi oleh Bapa Raja Liang yaitu Simon Tuniluhulima menjelaskan Liang yaitu Simon Tuniluhulima menjelaskan
bahwa pelantikan yang berlangsung pada 20 Juni 2002. Tim penelitian mendapat sebuah kepingan cakram VCD dokumentasi pelantikan bapa raja. Keping cakram tersebut dijadikan tim sebagai data sekunder yang melengkapi data wawancara dengan narasumber. Hasil dokumentasi tersebut merupakan sebuah manifestasi dari sebuah tradisi yang dipandang sakral dan masih berlangsung di tengah masyarakat hingga pada saat sekarang ini dengan menggunakan sebuah tinggalan arkeologi berbentuk batu pamali.

Fungsi kekinian dari penggunaan batu pamali tetap bersifat sakral karena masyarakat menjadikan hal tersebut sebagai simbol. Simbol tersebut menjadi terikat ketika bersatu dengan sistem religi dalam upacara pengambilan sumpah raja.

Simbol mampu mengubah suatu benda atau tindakan yang tadinya hanya tampak bersifat profan menjadi sesuatu yang lain. Simbol mengungkapkan aspekaspek terdalam dari kenyataan yang tidak terjangkau oleh alat pengenalan lain. Dalam suatu kelompok masyarakat biasanya terdapat orang yang dipercaya untuk memahami simbol-simbol tertentu seperti; kosmokonis desa, modalitas yang paling rahasia yang dibungkus dalam situasi historis komunitas desa, dan kecakapan khusus lainnya yang diperoleh karena inisiatif sendiri atau secara turun-temurun (Prasetyo, 2004 : 171).

Wallace mengemukakan bahwa relig merupakan seperangkat upacara yang diberi rasionalisasi mitos, dan yang menggerakkan kekuatan-kekuatan supernatural dengan maksud untuk mencapai atau untuk menghindarkan sebuah perubahan keadaan pada manusia atau alam (Wallace, 1966 107). Urutan ritual sendiri terdiri atas sejumlah kegiatan individual, sebagai conto pendeta adalah salah satu dari bagian kegiatan ritual yang mengatur tata cara penyampaian perasaan kepada kekuatan supernatural. Musik termasuk tari, nyanyian dan permainan instrumen adalah komponen lain dari ritual, disamping saji-sajian dan kurban.

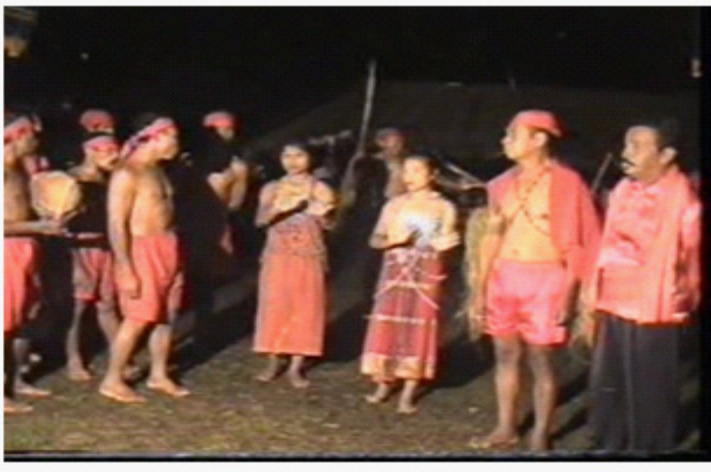

Gambar 5. Berdendang dan memukul tifa

(Sumber: Dokumen Balar Ambon 2012)

Gejala tindakan religi ditandai oleh dua hal pokok, yaitu kepercayaan dan ritus. Kepercayaan ditunjukkan dalan bentuk pandangan, dan dapat dicapai lewat penggambaran-penggambaran, sedangkan ritus lebih berbentuk modus-modus tindakantindakan tertentu (Durkheim, $1965: 29$ )

Faktor yang mempengaruhi masyarakat sehingga masih melakukan tradis pelantikan bapa raja menggunakan batu pamali dikarenakan hal tersebut merupakan sebuah eksistensi kebudayaan suatu kelompok dalam hal ini negeri Liang sebagai kelompok masyarakat Patalima. Masyarakat percaya bahwa Batu pamali (batu meja) yang masih ada sampai sekarang sebagai tempat yang 
dipercayai oleh mereka dalam melaksanakan segala ritual. Eksistensi tradisi pelantikan raja masih berlanjut hingga saat sekarang karena merupakan substansi sosial budaya yang inheren (berhubungan erat / melekat) sebagai kesatuan masyarakat bercorak Patalima.

\section{PENUTUP}

Berdasarkan uraian sebelumnya, dapat ditarik beberapa kesimpulan dari hasil penelitian yang dilakukan. Kesimpulan yang diperoleh adalah sebagai berikut:

Penggunaan batu pamali bersifat keramat karena masyarakat menjadikan hal tersebut sebagai ritus yang sangat sakral dan dipandang penting dalam komunal desa. Simbol yang terikat dan bersatu dengan sistem religi dalam setiap upacara / ritual yang dilakukan masyarakat desa. Hal tersebut yang membuat batu pamali masih difungsikan dalam ritual pelantikan bapa raja. Faktor yang mempengaruhi masyarakat sehingga masih melakukan tradisi pelantikan bapa raja menggunakan batu pamali dikarenakan hal tersebut merupakan sebuah eksistensi kebudayaan suatu kelompok dalam hal ini negeri Liang sebagai kelompok masyarakat Patalima.

Melalui penulisan ini diharapkan masyarakat desa Liang dan pemerintah yang terkait bersama-sama mengadakan pengamanan yang intensif terhadap artefak yang masih tersimpan dalam komunal masyarakat serta menjaga kelestarian tradisi megalitik yang dilakukan secara turun temurun.

Kekayaan lokal daerah ini harus selalu dijaga demi kepentingan ilmu pengetahuan yang berusaha terus mencari gambaran yang lebih sistematis dan mendalam untuk memberikan sketsa yang lebih luas mengenai tradisi megalitik dewasa ini.

$* * * * *$

\section{DAFTAR PUSTAKA}

Binford, Lewis R. 1972. An Archaeological Prespective. New York: San Fransisco: London Seminar Press.

Durkheim, Emile. 1965. "The elementary forms of the religious life". The Origin and Development of Religion.

Istari R. dan Sukendar H. dan Tim Peneliti. 1997. Situs Desa Aboru Kecamatan Pulau Haruku, Maluku Tengah. Jakarta: Pusat Arkeologi Nasional, Bagian Proyek Penelitian Purbakala Maluku.

Prasetyo, Bagyo. 2004. Religi Pada Masyarakat Prasejarah di Indonesia. Jakarta: Dinas Kebudayaan dan Pariwisata.

Ririmasse. M. 2008. Laporan Penelitian Persebaran Megalitik Di Pulau Nusa Laut Kabupaten Maluku Tengah. Ambon: Balai Arkeologi Ambon.

Soegondho, S. 1996. Penelitian Kepurbakalaan Desa Aboru, Kecamatan Pulau Haruku, Maluku Tengah. Jakarta: Pusat Penelitian Arkeologi Nasional. Bagian Proyek Penelitian Purbakala Maluku.

Soejono, R.P. 1996. "Jaman Prasejarah di Indonesia”. Sejarah Nasional Indonesia I. Departemen Pendidikan dan Kebudayaan. Jakarta: Balai Pustaka.

Sudarmika G.M. 2000. Laporan Penelitian Arkeologi Di Desa Iha Kecamatan Saparua Kabupaten Maluku Tengah. Ambon: Balai Arkeologi Ambon.

Sukendar, H. 1982. "Megalitik di Nias". Analisis Kebudayaan No. 2. Jakarta: Depertemen Pendidikan Kebudayaan.

Taurn, Odo Deodatus. 2001. Patasiwa und Patalima vom Molulukeneiland Seran und Seinen Beoners. Leipzig. Terjemahan Dra.Ny.Hermelin T tahun 2001. Ambon: Balai Kajian Sejarah dan Nilai Tradisional Maluku dan Maluku Utara.

Wales, H.G. Quaritch. 1953. The Mountain of God, a Study in Early Religion and Kingship. London: Bernard Quaritch, Ltd.

Wallace, Anthony F.C. 1966. Religion: An Anthropological View. New York. Random House. 